\title{
ART IN THE WORLD WIDE WEB (INVESTIGATION ON TWO INTERACTIVE ARTWORKS OF MARK NAPIER)
}

\author{
Farinaz Saberian \\ $\mathrm{PhD}$, Department of Art, Faculty of Art Research, Alzahra University, Tehran, Iran \\ saberian94@gmail.com
}

\begin{abstract}
Today, alienation of the art and technology has come to an end and inevitable movement of the world toward digital culture has also affected the art. In the current study, two internet-based artworks created by Mark Napier, the contemporary American artist and one of the pioneers of Internet art in the U.S., were selected and analyzed. The main point of the study is investigating the role of audience and its interaction with his artworks, as well the effect of technology in the process of artistic creativity. By presenting his interactive art project on the Internet, Mark Napier has gone beyond the domain of exhibitions and museums and has utilized modern technology to make contact with the audience. In his artworks, audience is the inseparable component of the work and the process of creation finds more importance than the prototype and final outcome. In the creation process, the importance of active participation of the audience and artist's consideration for cultural, political and social issues can be observed.
\end{abstract}

Keywords: artwork, interaction, internet art, Mark Napier

\section{INTRODUCTION}

Nowadays, art definition has changed compared to the past, since it has moved toward a new direction and is using different means of expression. Art experiences new concepts every day which are based on modern Media. Variety of Media and different types of visual expression, complexity of different steps of creation of many artworks and their integration with science and technology makes it difficult to judge in the fields of art and aesthetics. Over the past few decades, new artistic movements and events have been formed following the collapse of previous perceptions of art and presentation of new definitions including internet art. The outcomes of many main artistic movements and events and their new definitions can be found in the way of appearance of computer arts and related types. They are the most complicated today's art forms in terms of applying different dimensions of science and technology, as in the recent years different forms of computer and digital art are seen as the most remarkable ways of visual expression to realize creative artists' impossible dreams and contemplations. New art has changed the aesthetic perceptions fundamentally and has showed that artworks are not only some beautiful objects, but they also may be a set of philosophic thoughts and concepts that translates natural events and numerous contemporary facilities into the artworks and the artist is not limited to a certain method, but the originality of ideas becomes important. Edward Louse Smite states: "using all new tools and facilities, new art aims to insist on its consideration and attention for humanitarian and social issues and important global subjects such as freedom, environment, nuclear hazards, feminism, technology, man-made disasters and world war massacres (Lucie Smite, 2005).

\section{LITERATURE REVIEW}

Many researches have been conducted on the new art, digital technology and art on the Internet which often are written in English and some have been translated into Persian recently, such as "new Media in the art of the $20^{\text {th }}$ century" by Michel Rush (2010) and "the contemporary art" by Isabella De Maison 
Rouge (2010). Moreover, several pages in some related journals was assigned to the new art topic and several research projects about the new art, internet art and interactive art has been published in these pages. The "future art" is among journals which present valuable information regarding the contemporary art. However, no research has been conducted on the interactive internet art and artworks of the American artist, Mark Napier.

\section{RESEARCH METHOD}

The present study is conducted in the descriptive- analytical method and data were collected using digital and written references, and internet.

\section{Contemporary art}

Understanding the contemporary art seems to be a difficult task. However, with the aid of organizations such as museums and artists' efforts, public awareness about the contemporary art will certainly increase over the next few decades. In description of the contemporary art, it can be stated that it has various free expressions which cannot be placed in a specific form (De Maison Rouge, 2010, 95). The term of contemporary art emerged in 1980s and now it includes the current and live art, while in fact this branch of art covers 1960-1969. Contemporary art manifests itself using the obvious border between classic trainings of art and appearance of new techniques including mixed media and multimedia, which has caused the expansion of art environment and complexity of artistic expression (Ibid). Increasing development of technology in the contemporary period, remarkable evolution of communication technologies and expansion of new media such as image, video and internet have resulted in the emergence of new media art. In the process of new media art creation, new medium technologies have been employed. Digital art, virtual reality, internet art and animation are subsets of the new media art (www.wikipedia.org).

\section{Digital technology as a medium}

The relentless advance of the world toward digital culture encompasses the art as well and it can be said that a stressful relationship has been created between the art and technology in this era. Digital technology in which computer is main tool in all fields of the contemporary art includes film, photography, electronic music, computer information and many other categories and the new power that digital technology brings to illustration art makes it extremely flexible. Any component of the image can be modified when it is converting to the digital language in the computer, since the image converts into "information" in the computer and all parts of it can be manipulated. Art should encompass changing world which exists inside the computer and new world that is provided by computer. Interactive art world with virtual reality is dependent on the viewer for completing the concept. When Dushan suggested that the artwork depends on the viewer to complete the concept, he never knew that at the end of the century some artworks (such as interactive films) are dependent on viewers not only to complete the concept, but also to initiate the artwork and give the meaning and content to it. "Interactive" is the most common term to describe the type of art in the digital era (Rush 2010, 191-194). "The use of digital technology as an art medium means the creation of artworks that follow digital policy since the very first stage of the production to its presentation, and discover natural facilities that these tools provide. Special facilities that are offered by digital medium introduce a certain form of aesthetics; for example, digital medium has some features such as being interactive, cooperative and dynamic. In some artworks, the audience interacts according to criteria which are set by the artist and in some others, the criteria are set by the audience or they play role in live and scheduled performances distantly. In some cases, the visual work of art is created by the audience who contributed in that artwork. Installation art, Film, video art, animation and internet art are among forms on which a digital artwork can be placed (Paul, 2003).

\section{Art in the World Wide Web}

Internet art (often named as net art) is a kind of digital art which is available through internet. This form of art ignores the conventional influence of the gallery and museum and obtains aesthetic experiences 
using internet. In many cases, the viewer interacts with the artwork. Artists who work in this way are called "net artists". Internet art can occur outside the technical structure of the internet, such as the times when artists use special social customs or a conventional culture on the Internet for outside the internet projects. Internet art often is interactive, cooperative and multimedia and can be used to publish a political or social message using human interaction. The term of internet art does not specifically refer to an art which can be easily digitized, uploaded and visible through internet. This can be done using an internet browser, like images that are in an online gallery among submitted images. This kind of art relies more or less on internet basically for its existence and uses some interactive aspects and connection relationship with several social and economic cultures and subcultures. This art refers to internet as a whole and not as web-based artworks (Ippolito, 2010, 10)

\section{History of net art movement}

Net art movement arose in the context of the wider development of Internet art. Thus, net art is more than a movement and is considered as a critical and political turning point in the history of art on the Internet and is more significant than a certain style or genre. Primary forms of net art movement include international Fluxus movements (Nam June Pike) and Avant-garde movement (Mark America). Avantgarde movement was widely recognized since 1993 through popular Alt-x website. "Net art" term was coined by Pit Schultz in 1995 most probably, but it also is attributed to Vuk Cosic (Green, 2004, 9). Maybe we can consider artists who put aside the drawing canvas and chose more mobile and active media as pioneers of the internet art, among them "Nam June Bike" from Korea can be mentioned who selected the TV mass media and use it as an interactive and active canvas. Internet art is indebted to the conceptual art regarding its emphasis on viewers' cooperation and participation, information transfer and use of network systems. Thus, the "concept" and artist's thought are still important instead of art object or the way of its presentation. Moreover, one of the effective areas on the internet art is the art of performance. It is a kind of live performance by artist itself and being live is its characteristic. Live performances are possible on the internet considering the mobility of time and place. In such projects, artists and individuals connected to the net participate from their own countries in the project and contribute to its overall performance. Internet art was at its popularity peak during 1996-1998 in the world, when attention and enthusiasm of the people to the internet and internet art was at its climax. In the last decade, the first movements of the internet art formed in Europe using opinions of critics and a group of artists who knew the internet-based art as the main theme of the work and a movement as "net. Art" was organized by them. This art established and developed its own artistic world in which many online artists and critics were present. At the beginning, Internet media was not so complicated and mainly had more text features than visual ones. So that early internet artworks were more conceptual (Propper, 1993, 56). Roy Ascott was the first artist who created the first internet artwork. His artwork "La plissure du texte" was displayed in the "Electra" exhibition in the Paris new art museum, 1993. With the development of the computer in 1980 and appearance of "web" in 1990, many artists joined the internet and they were most independent of art institutes and in opposition with the official culture of that time. During 1994 to 2000, many museums were involved in archiving and publication of the internet art. International online networks for artists had key role in this process such as "The Thing", "Adaweb" and Alt-x that were established by "Volfgang Staehle", "Benjamin Weil" and "Mark Amerika", respectively (Greene, 2004, 13).

\section{Mark Napier}

Mark Napier (born in 1961, Springfield, New Jersey) is the pioneer of net art in the USA and is known for creation of online interactive artworks) who challenged conventional definitions of art. He created the potatoland.org, his own computer workshop in which his many artworks can be found. He lived and worked in the New York. He graduated from Syracuse University in fine arts in Bachelor of Science. He was trained as a painter and works as a self-educated programmer in financial markets of the New York. He set up his first web site together with Levi Asher. In 1997, he established potatoland.org, his online 
workshop for interactive work, where he examined the use of computer soft wares as art tools (www.marknapier.com).

\section{Brief description of Mark Napier}

(Mark Napier new media artist, pioneer on the Internet art)

Important events (highlights)

Internet art, 1998 (the interactive artworks based on internet, see the potatoland, shredder, riot)

Net flag, 2002 (it is in the permanent collection of Guggenheim museum in the New York)

Whitney Biennial, 2002 (riot in the Whitney Biennial)

Walled parts, 2005 (generator or productive art in the Bit forms gallery (see smoke, empire)

PAM, 2009 (Venus 2.0 in Berlin Dam)

Potatoland.org (internet art projects including paper shreds (shredder), Rebel, net flag)

\section{Some citations from Mark Napier}

"I am creating "internet art". My Internet artworks are connected to the internet and are designed in the net environment for existence. Acquisition, domination, territory and communication ideas are investigated in my profession."

"I do this work using a software innovation that speaks directly on the Internet and is assigned to text, image and information which complete the Internet. These are used by software as row materials in order to create an art experience. Since I use programming languages to create these computer mediators, codding and programming processes are allowed to produce unforeseen features that would add other aspects to the work. Technology reveals the features. Events and errors which occur in the program create some interesting and unpredicted features."

"Such creative chaos is developed in works. My works are not targets, but are mediators. Users participate in the works and disrupt the customs of acquisition and domination. Viewers form, develop or change the artwork unpredictably through interaction with the artwork."

"User is the required part and supplement of the design. Technology provides a common space as a mediator through which the user is responsible for an artistic process. Artwork is not an object; it is a process, a mediator, an invitation to participate in a creative action (www.marknapier.com)."

\section{The waiting room}

Mark Napier's approach and attitude to the internet art reflects his background as a painter, since complete awareness of color and form can be observed in his works. As mentioned before, he believes that audience forms, changes and develops the artwork when interacting with that. The concept of group interaction can be seen in one of his works titled "the waiting room". The waiting room is an artistic software project which is described as "animation" by the artist. In this project, user input (through a tangible walled screen) builds abstract art and theater of shadows.

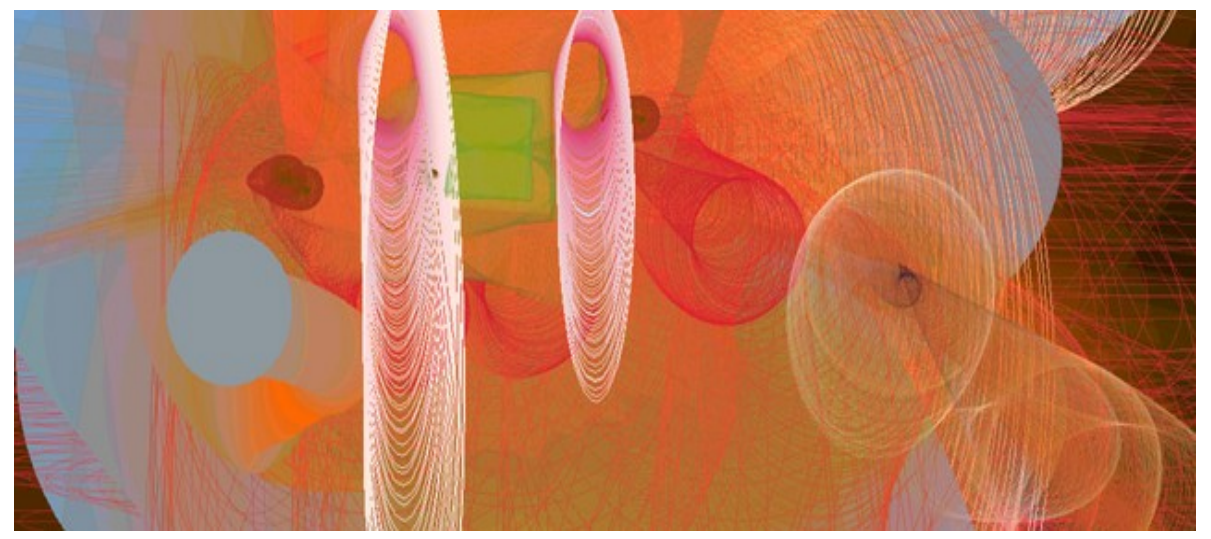

Submit Date: 01.05.2016, Acceptance Date: 20.06.2016, DOI NO: 10.7456/10603100/002 
Figure1. Waiting room (May $\left.4^{\text {th }}, 2002\right)$
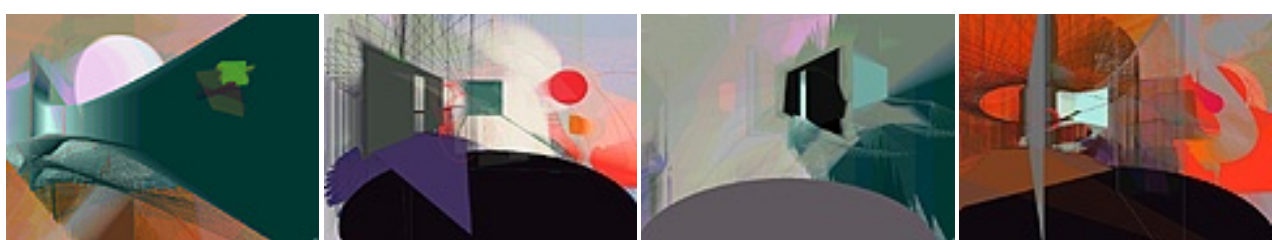

Figure2. Four images from Monitor
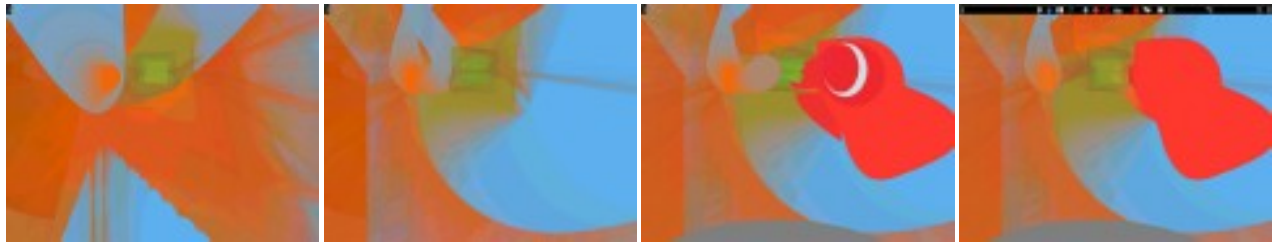

Figure3. Images taken within 1 minute

In order to perform this project, Mark Napier cooperated with Bit forms gallery (a gallery in the New York which is assigned to the media art). 50 users were to receive a copy of his artwork on CD-ROM. Each sample of "the waiting room" relates with others through the internet. So, when a user interacts with an artistic work, its result will appear on the screen of other users (Tribe and Jana, 2000, 70). The waiting room is a virtual space in which 50 users participate through internet. Visitors of the virtual space take part in an animation and their action form the art work and perform it. They can change the screen from dark to light or laminar to turbulent according to their moods. Each click creates an image, wall, shadow or a sign of architecture with fading light (www.marknapier.com). The waiting room is available on CDROM. For detailed information visit the bitforms.com or contact the napier@potatoland.org.

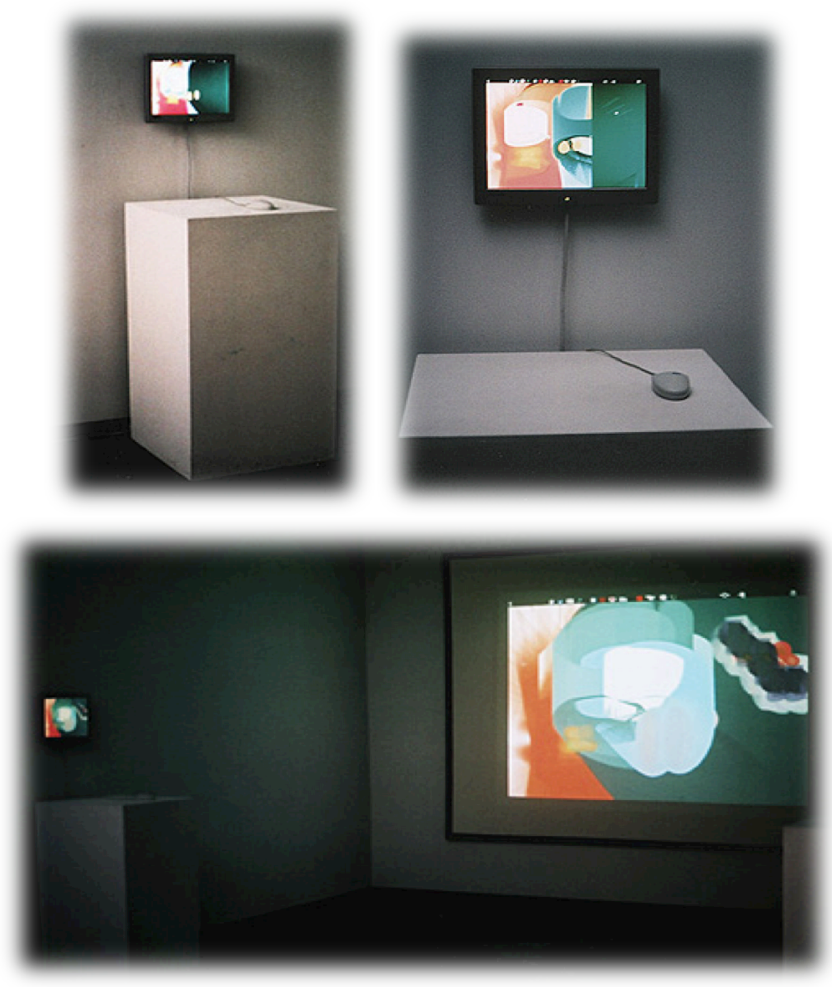

Figure4. Scenes from “Waiting Room” Project by Mark Napier 


\section{Net flag}

Net flag is one of Mark Napier's works which is located in permanent collections of New York Guggenheim Museum. It is an Internet-designed flag. Every nation in the world has its own flag that identifies the nation's realm and identity and it is symbol of domination on new kingdom. One of most memorable images of $20^{\text {th }}$ century was the flag of USA which was placed in rocky land of the Moon. It is a symbol of earthly kingdom that detects the whole planet as well as showing possession claim over Moon. In the new millennium, we see some nations claim possession for the new territory: the Internet. This visual area is not a geographical area; it is a new field with particular capabilities. It is a Space that its foundation is established by Man and carries potential data, group uniform and political and economic profit. Nations and terrorists equally use internet to advance their work plans. People who possess internet can create new space and control its particulars. (Whether hardware or software), are able to access internet net via different ways or constrain them. In this new space, lie the Internet users: the lead pioneers and next visitors who study the facilities of this global space. These people enjoy unique freedom within classified range of internet to discover modern concepts out of personal and national identity. The flag is a symbol for determining the identity territory of each nation and a variety of international flags are studied by using visual language. An online flag that plays intermediary role can make possible the use of shape language and exciting colors in internet artistic work for everyone who have access to internet. Someone who watches internet flag not only sees it but also can reflect his data change, climate, nonpolitical and political programs. The flag which is produced in this process is a symbol and small territory: a place to encounter, request, communicate and display.

Net flag, Guggenheim; R. Salomon Museum (New York) was among permanent works of the exhibition" (www.emedia.art).
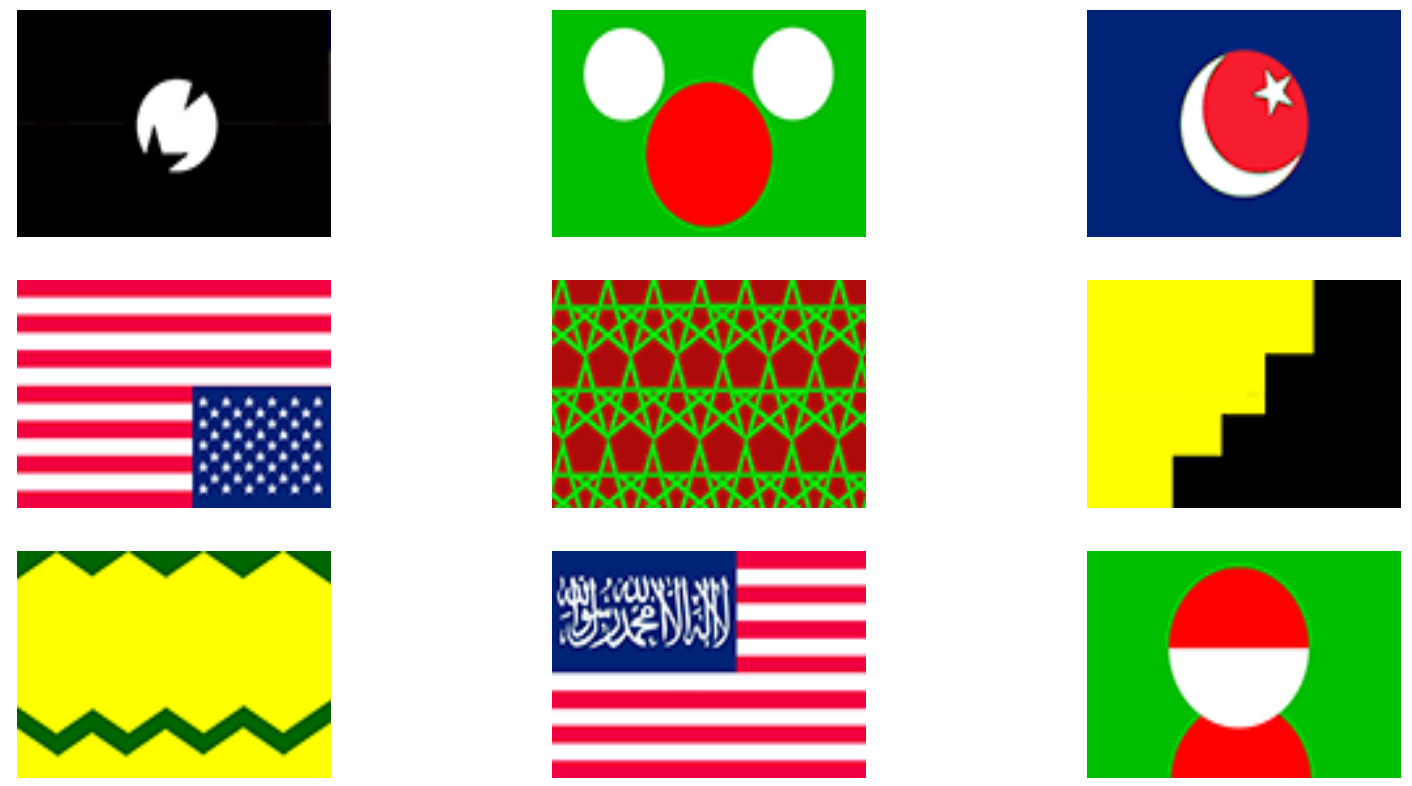

Figure5. Selected flags from Net flags (2002-2012)

Guggenheim museum in New York, plays a vital role for achieving visual culture and orders the internetrelated artistic works to realize bright future of new media especially internet. The museum has suggested two new works of internet art on February 18, 2002: Internet flag, by Mark Napier and disclosed object, by John .F. Simon. Acceptance of these two works in permanent collection of museum indicates the last effort of this institute to achieve their goal. Since February 18, an introduction plan for the projects and 
internet art is observable in http://www.guggenheim.org. " Thomas Krens" the manager of Guggenheim, R. Salomon institute says:

"The art created for internet has traveled a long path in a short time. In less than a decade, online art, has turned into a great movement that watched by many viewers. It can be said when we look at internet art, actually we will have passing looking to new path of art in the $21^{\text {st }}$ century".

Internet symbol is a new territory for internet that is created by people from different geographical region and various religious backgrounds. Flag design changes from similar list by manipulating of user and selecting imprint, colors, signs and line at the same time. Moreover, internet flag project has a historical browser and this feature can provide access to transformation process and symbolic values in this internet project. As the number and rate of signs indicating "peace", "bravery", or "blood" and they are used on flags by many users, which are visible in an instant (www.guggenheim.org).

Guggenheim. R. Salomon museum net. Flag-a flag for internet
* Change in net. Flag
* Structure or anatomy of flag
* Available flags on the net
* Statistics
* About flags
* Title
* Guidance

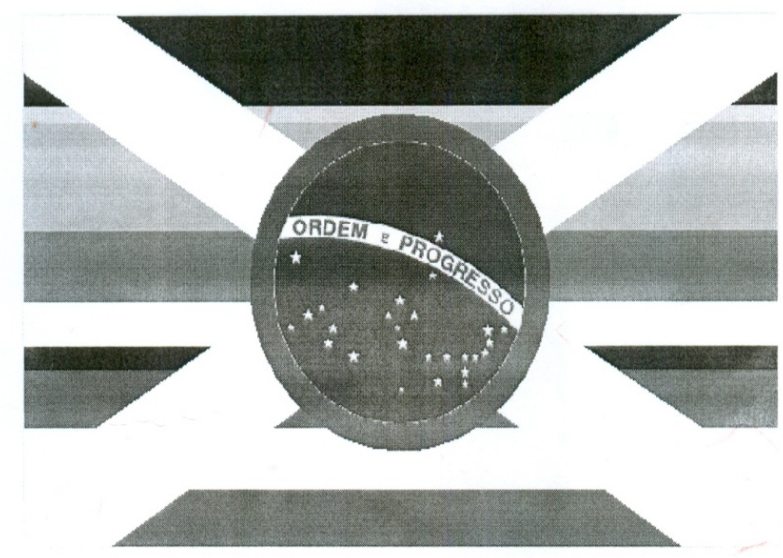

Figure6. Current flag designed in Jan $28^{\text {th }}, 2012$ (7:45 AM)

\section{CONCLUSION}

Growing advance of technology in current age, emergence of mass media, especially internet and visual space, is the reality of our life today. As the world progresses, new artists should also adapt themselves to technological advancements. In art category, relation between thought, ideas and works which is created afterward require using suitable tools to state the idea. The use of computer to create video or imaginary spaces and emergence of movement called digital art or computer art does not have a long history in the world; however, it has been transformed into a pervasive movement in a short time and is entering into painting art, and there is a possibility that it brings everything in this area under control. Internet art that is sometimes called "Net Art" is a kind of digital art that is displayed on the internet. The art is sometimes interactive and cooperative and it is based on multimedia arts. The term "Internet art" usually refers to a branch of art that is utilized by the possibility of digital art and it is displayed online later. Internet art considers public audience and tries to remove art and non-art boundaries created by museum and gallery to transfer the art from closed walls of museum and gallery to computer screen. In Net Art works, not 
only completed work is depicted, but its multimedia capabilities also help working process and show artist procedure. At the same time, the audience is able to interact and cooperate in completion process of artistic work. Internet observance through one of computer mediators or intermediary sites like Mark Napier seems like a brief glance over a perspective of unlimited visual possibilities. "Waiting room" is a place in virtual world where fifty users don't know each other, and they get acquainted with each other by internet, software and artistic work. In such space, work and the influence of these persons cause activate and form artistic art. Users are inspiring agents who cause creation of different appearance of shade and light in artistic work by their feeling and any click, and also can change darkness into brightness and calmness into unrest. The role of incidence is also observable in performance process of the work. There is sense in real world and at a waiting room that what will happen next. In this virtual space, what is about to happen depends on users. Napier created "internet flag" as symbol of new territory including people with different ideology and belong to different geographical areas. Design of the flag has constantly changed and it is manipulated by internet users, because they can select designs and paintings such as star, color, sign and clear images from a list which contains design of similar flags. While observers cooperatively help designing flag, flag identity changes and nations' emblem and sign temporary interference with other sign or emblem. The project allows observer to make their own flag and store it in their virtual territory. In Napier works, the audience's status equal to the artist and steps in the way of discovery and intuition and cooperates in the recreation of artistic work that expert knowledge is not required in imaginary phase. Using new technology does not diminish the attractiveness and value of these works, since this technology is utilized to express mental and conceptual capabilities of the artist and its audience. There is a kind of worldview in the works of this group of artists and numerous meanings may be conveyed to the audience. By changing the form of flag in internet flag project and audience's interaction, vague and disordered flag design, in which a national identity emblem is changed into another flag and this, can be a metaphor of chauvinism futility or combination of national, political and domestic identity of different countries. The majority of new artworks present the forms and concepts and daily life forms to express new insights, with individual creativities. Thoughts that articulate the contemporary state of the world have bonded with his factors and retell his/her age and era, as these features can be observed in Mark Napier's works. There is a possibility that fancy aspect and application of new technology appears in his work, however his idea and worldview is evident beyond his Internet art works.

\section{DEFINITIONS}

Fluxus, taken by Latin word means " process", international network of artist, musician and designer, and it is mentioned for media combination and different branches of art in 1960. They were involved in NeoDad, music and visual arts and also literature, civil planning, architecture and design. At some cases, Fluxus is described as internal media.

Nam June Paik, one of the distinguished artist of visual arts who found video Art by combining TV images, statute, music and live player in 60 s and died 5 years ago at the age of 74 . Paik was born in Korea and starts his work as a musician in Japan and Germany. He was interested in electronic arts and phonetic process that we can mention fluxux group and acquaintance with artists like John cage and Josef Boyez. He spends practice the initial years of his presence in Germany and continues his experience in performance art and video art, after moving to New York in 1964.

\section{REFERENCES}

De Maison, R. I. (2010). Contemporary art, Arab Zade Jamal, University of Art, Tehran.

Greene, R. (2004). Internet Art, Thames \& Hudson Ltd, London.

Ippolito, J. (2002). Ten myths of Internet art, Leonardo, 35(5), 485-498.

Lucie Esmit, E. (2005). Globalization and new art, Ali Reza Sami Azar, the second publication, Tehran. Paul, C. (2003). Digital art. London, ed. 
Popper, F., \& Hemingway, B. (1993). Art of the electronic age (pp. 107-108). London: Thames and Hudson.

Rush, M. (2010). Modern media in $20^{\text {th }}$ century art, Bita Roshani, the first publication, Tehran. Tribe, M \& Jana, R. (2009). New Media Art, UTA Gooseneck (ED), Taschen. 